\title{
Innovation and Economic Growth: Does Internet Matter? ${ }^{1}$
}

Sayef Bakari ${ }^{a}$

a University of Tunis El Manar, Tunisia, ～bakari.sayef@yahoo.fr, https://orcid.org/0000-0002-5395-4348

ARTICLE INFO

Research Article

2021, Vol. 3(2), 109-116

e-ISSN 2667-5927

Article History:

Received: 19.03 .2020

Revised: 21.03.2021

Accepted: 29.04.2021

Available Online: 30.04 .2021

JEL Code: 01, 03, 031

Keywords: innovation, economic growth, internet
Innovation and Economic Growth: Does Internet Matter?

Abstract

We analyze the relationship between economic growth and innovation taking into consideration the importance of the internet. To do so, we use a panel ARDL model, with data on a sample of 76 developed and developing countries in different geographic regions for the 1995-2016 period. Our findings provide empirical evidence of the positive role of innovation and internet in economic growth and the positive role of economic growth and internet in innovation. From these results, we derive several basic policy conclusions.

To cite this document: Bakari, S. (2021 Innovation and Economic Growth: Does Internet Matter? BILTURK, The Journal of Economics and Related Studies, 3(2), 109-116. doi: 10.47103/bilturk.706165

\footnotetext{
${ }^{1}$ Acknowledgments: The author would like to thank Mediterranean Universities Union, coordinator of the Erasmus + project for their supports in providing all the necessary conditions to carry out this work.
} 


\section{Introduction}

Since ancient times, humans tend to think of new and better ways of doing things and experimenting with them in practice. This phenomenon is called innovation. These include: inventing new ways to produce goods, discovering services that enhance productivity, create jobs, bring in new technologies, create new products that help meet global challenges, improve people's quality of life, and achieve economic growth \{see Schumpeter (1932), Romer (1986, 1990) and Stokey (1995), hasan and Tucci (2010), Mabrouki (2018)\}

The Internet is a comprehensive technology that supports the real economy by improving access to market information, facilitating business processes and creating new jobs, and enhancing the company's performance. All these benefits have made the Internet one of the cornerstones of economic growth \{see Choi and Yi (2009), Tripathi and Inani (2016), Zaghdoudi (2017), Saidi and Mongi (2018)\}.

For these reasons, we will empirically investigate the potential relationship between innovation, internet and economic growth by using a panel of data of 76 countries. The rest of the paper is organized as follows. Section 2 presents the methodology and data. Section 3 presents the main empirical results, followed by conclusions and policy analysis in section 4.

\section{Data and Econometric Model}

The data set used in this paper includes 76 developed and developing countries ${ }^{2}$ for the period 1995 to 2016 . The choice of the sample size and the period of study depend on the belief of data. All data are obtained and calculated from the World Bank database. We take real gross domestic product as proxy to express economic growth, patent applications (residents) as proxy to measure innovation and individuals using the internet to express the usage of internet.

Panel ARDL Model is used to explain the relationship between economic growth and innovation taking into consideration the importance of the internet. The long run relationship between innovation and economic growth could be in view by the following model:

$$
\log (\mathrm{Y})_{\mathrm{it}}=\delta_{1 \mathrm{it}}+\boldsymbol{\beta}_{1 \mathrm{i}} \log (\mathrm{I})_{\mathrm{it}}+\beta_{2 \mathrm{i}} \log (\mathrm{PI})_{\mathrm{it}}+\varepsilon_{1 \mathrm{it}}
$$

\footnotetext{
${ }^{2}$ Algeria, Argentina, Armenia, Australia, Austria, Bangladesh, Belarus, Belgium, Brazil, Bulgaria, Canada, Chile, China, Colombia, Croatia, Czech republic, Denmark, Ecuador, Egypt, Estonia, Finland, France, Georgia, Germany, Greece, Guatemala, Hong Kong, Hungary, Iceland, India, Indonesia, Iran, Ireland, Israel, Jamaica, Japan, Kazakhstan, Kenya, Korea, Kyrgyz, Latvia, Lithuania, Luxembourg, Macedonia, Madagascar, Malaysia, Malta, Mexico, Moldova, Netherlands, New Zealand, Norway, Pakistan, Peru, Philippines, Poland, Portugal, Romania, Russian, Saudi Arabia, Singapore, Slovak, South Africa, Spain, Sri Lanka, Sweden, Swiss, Thailand, Tunisia, Turkey, Ukraine, United Kingdom, United States, Uruguay, Uzbekistan, Viet Nam. 
$\log (\mathrm{I})_{\mathrm{it}}=\delta_{2 \mathrm{it}}+\boldsymbol{\beta}_{1 \mathrm{i}} \log (\mathrm{Y})_{\mathrm{it}}+\boldsymbol{\beta}_{2 \mathrm{i}} \log (\mathrm{PI})_{\mathrm{it}}+\varepsilon_{2 \mathrm{it}}$

Where Log $(\mathrm{Y})$ is natural logarithm of real gross domestic product (2010 constant US \$), Log (I) is natural logarithm of Patent applications (residents), Log (PI) is natural logarithm of Individuals using the Internet (millions of inhabitants), $\delta$ is an intercept term, $\beta 1$ and $\beta 2$ are the long run elasticity estimates, ' $\varepsilon$ ' is the term error, ' $i$ ' is the individual dimension of the panel (the country) and ' $t$ ' is the temporal dimension.

\section{Empirical Analysis}

Before the proffer of the empirical outcomes, there is some pre-tests of data are mostly deemed very radical to furnish some prerequisites about the link of the attacked variables.

Table 1: Descriptive statistics

\begin{tabular}{lcccccc}
\hline \hline \multicolumn{1}{c}{ Variables } & \multicolumn{3}{c}{ At level } & \multicolumn{3}{c}{ At log level } \\
\cline { 2 - 7 } Mean & $\mathrm{Y}$ & $\mathrm{PI}$ & $\mathrm{I}$ & $\mathrm{LOG}(\mathrm{Y})$ & LOG(PI) & LOG(I) \\
Median & $1.68 \mathrm{E}+16$ & 16131338 & 14333.86 & 26.05773 & 14.52950 & 6.291015 \\
Maximum & $1.85 \mathrm{E}+11$ & 3331488. & 548.0000 & 25.94555 & 15.01893 & 6.306269 \\
Minimum & $1.69 \mathrm{E}+18$ & $7.33 \mathrm{E}+08$ & 1204981. & 41.97246 & 20.41327 & 14.00197 \\
Std. Dev. & $2.44 \mathrm{E}+09$ & 75.19898 & 1.000000 & 21.61527 & 4.320138 & 0.000000 \\
Skewness & $1.52 \mathrm{E}+17$ & 51179250 & 67760.69 & 2.650799 & 2.567506 & 2.371794 \\
Kurtosis & 9.366229 & 8.395998 & 8.762379 & 3.079506 & -0.937932 & 0.493995 \\
Jarque-Bera & 59.95609 & 92.18205 & 109.0698 & 18.77793 & 4.351394 & 3.394638 \\
Probability & 0.000000 & 0.000000 & 0.000000 & 0.000000 & 0.000000 & 0.000000 \\
Observations & 1672 & 1672 & 1672 & 1672 & 1672 & 1672 \\
\hline \hline
\end{tabular}

Table 1 show that all variables have a probability of refusal less than $5 \%$, which tick that they are all esteemed during the period of the study. Skewness and Kurtosis coefficients undergo variables that follow a normal distribution.

Here we explain the correlation between all the core variables of the study. Table 2 shows that economic growth $(\mathrm{Y})$ correlates positively with innovation $(\mathrm{I})$ and with internet (PI). Also innovation (I) correlates positively with internet (PI). 
Table 2: Correlation matrix of variables

\begin{tabular}{cccl}
\hline \hline & $\mathbf{Y}$ & $\mathbf{P I}$ & $\mathbf{I}$ \\
\hline \hline $\mathbf{Y}$ & 1 & & \\
$\mathbf{P I}$ & 0.3664 & 1 & 1 \\
$\mathbf{I}$ & 0.3284 & 0.7914 & 1 \\
\hline \hline
\end{tabular}

Before modeling, the LLC test (Levin et al., 2002), IPS test (Im et al., 2003), ADF (Maddala and Wu, 1999) and PP test (Maddala and Wu, 1999) are used to arbitrate whether the three variable $\log (\mathrm{Y}), \log (\mathrm{PI})$ and $\log (\mathrm{I})$ have the unit root or not.

Table 3: Panel unit root test results

\begin{tabular}{|c|c|c|c|c|c|c|}
\hline \multirow{2}{*}{$\begin{array}{l}\text { Unit } \\
\text { Root } \\
\text { Test }\end{array}$} & \multicolumn{2}{|c|}{$Y$} & \multicolumn{2}{|c|}{ PI } & \multicolumn{2}{|c|}{$I$} \\
\hline & C & CT & $\overline{C C}$ & $\mathrm{CT}$ & $C$ & CT \\
\hline \multirow[t]{2}{*}{ LLC } & $(3.01279)^{* * *}$ & $(14.8070)^{* * *}$ & $(500.414)^{* * *}$ & $(45.9574)^{* * *}$ & $(3.75976)^{* * *}$ & $(5.08084)^{* * *}$ \\
\hline & {$[20.9662]^{* * *}$} & {$[20.5875]^{* * *}$} & {$[37.8665]^{* * *}$} & {$[14.3247]^{* * *}$} & {$[34.4880]^{* * *}$} & {$[29.9135]^{* * *}$} \\
\hline \multirow[t]{2}{*}{ IPS } & (3.06818) & $(3.66616)^{* * *}$ & $(41.5605)^{* * *}$ & $(25.1022)^{* * *}$ & $(1.58880)^{*}$ & $(4.82744)^{* * *}$ \\
\hline & {$[18.5228]^{* * *}$} & {$[15.0249]^{* * *}$} & {$[21.7738]^{* * *}$} & {$[17.3140]^{* * *}$} & {$[32.1528]^{* * *}$} & {$[28.0894]^{* * *}$} \\
\hline \multirow[t]{2}{*}{ ADF } & $(175.635)^{*}$ & $(187.067)^{* *}$ & $(2262.21)^{* * *}$ & $(666.439)^{* * *}$ & $(229.703)^{* * *}$ & $(273.358)^{* * *}$ \\
\hline & {$[618.750]^{* * *}$} & {$[15.0249]^{* * *}$} & {$[1200.36]^{* * *}$} & {$[590.569]^{* * *}$} & {$[1091.98]^{* * *}$} & {$[867.084]^{* * *}$} \\
\hline \multirow[t]{2}{*}{ PP } & $(241.916)^{* * *}$ & (134.694) & $(5655.65)^{* * *}$ & $(2901.68)^{* * *}$ & $(237.161)^{* * *}$ & $(262.181)^{* * *}$ \\
\hline & {$[1279.42]^{* * *}$} & {$[500.414]^{* * *}$} & {$[672.960]^{* * *}$} & {$[1059.94]^{* * *}$} & {$[2070.10]^{* * *}$} & {$[2170.73]^{* * *}$} \\
\hline Decision & \multicolumn{2}{|c|}{ I(1) } & \multicolumn{2}{|c|}{$I(0)$} & \multicolumn{2}{|c|}{$I(0)$} \\
\hline \multicolumn{7}{|c|}{ Note: $* * * * *$ and ${ }^{*}$ denote significances at $1 \%, 5 \%$ and $10 \%$ levels, respectively; } \\
\hline \multicolumn{7}{|c|}{ () denotes stationarity in level; } \\
\hline \multicolumn{7}{|c|}{ [ ] denotes stationarity in first difference; } \\
\hline \multicolumn{7}{|c|}{ 'C' denotes Constant; } \\
\hline ' $C T$ ' deno & stant & & & & & \\
\hline
\end{tabular}

Table 3 reported the estimated results of unit root tests, including the LLC test, IPS test, ADF-F test including the LLC test, IPS test, ADF test and PP test. It is obvious from results that, some of the data sets are integrated of (I (0)) or (I (1)). Therefore, it is suitable to run out a cointegration test using these variables.

Different cointegration tests are used to determine cointegration among variables. We used the Kao (2007) panel cointegration test. This test can be used in cases of the existence variables integrated in different order. 
Table 4: Cointegration test

\begin{tabular}{lcc}
\hline \hline \multicolumn{3}{c}{ Kao Residual Cointegration Test } \\
\hline \hline & t-Statistic & p-values \\
ADF & $9.898751^{* * *}$ & 0.0000 \\
Residual variance & 3.431267 & \\
HAC variance & 0.124783 & \\
\hline \hline
\end{tabular}

Table 4 shows the results of the Kao (1990) panel cointegration test. The results denote that the variables in the model are cointegrated, because $p$-value is smaller than 0.01 . Hence, a long-run equilibrium relationship occurs between log $(\mathrm{Y}), \log$ (PI) and $\log (\mathrm{I})$.

We have estimated Equations (1) and (2) for panel ARDL estimation. The results of the panel ARDL tests are shown in Table 5 and Table 6.

Table 5: ARDL results when economic growth $(Y)$ is the dependent variable

\begin{tabular}{lllll}
\hline \hline Variable & Coefficient & Std. Error & t-Statistic & Prob. $^{*}$ \\
\hline \hline Long Run Equation & & & & \\
LOG(I) & $0.000915^{* *}$ & 0.000431 & 2.121690 & 0.0343 \\
LOG(PI) & $0.001638^{* * *}$ & 0.000246 & 6.663952 & 0.0000 \\
Short Run Equation & & & & \\
\hline \hline ECT & $-1.205078^{* * *}$ & 0.141244 & -8.531861 & 0.0000 \\
DLOG(Y(-1),2) & 0.383332 & 0.111870 & 3.426581 & 0.0007 \\
DLOG(Y(-2),2) & 0.099865 & 0.090280 & 1.106170 & 0.2691 \\
DLOG(Y(-3),2) & 0.079354 & 0.050295 & 1.577759 & 0.1151 \\
DLOG(I) & 0.456332 & 0.416889 & 1.094611 & 0.2741 \\
DLOG(I(-1)) & 0.102952 & 0.240628 & 0.427849 & 0.6689 \\
DLOG(I(-2)) & $0.556374 *$ & 0.291745 & 1.907053 & 0.0570 \\
DLOG(I(-3)) & 0.391715 & 0.526913 & 0.743415 & 0.4575 \\
DLOG(PI) & -0.638587 & 0.478591 & -1.334307 & 0.1826 \\
DLOG(PI(-1)) & 0.724769 & 0.580651 & 1.248202 & 0.2124 \\
DLOG(PI(-2)) & -0.920203 & 0.721665 & -1.275110 & 0.2028 \\
DLOG(PI(-3)) & 0.448220 & 0.502740 & 0.891554 & 0.3730 \\
C & $-0.004350 * * *$ & 0.028199 & -0.154270 & 0.8774 \\
\hline \hline
\end{tabular}

Table 5 reports the output of ARDL estimation of Equation (1). Long run equation results shows that innovation log (I) and innovation log (PI) have a positive and significant impact on economic growth. The coefficient of innovation is 0.000915 which indicates that $1 \%$ increase in innovation leads $0.000915 \%$ increase in economic growth. The coefficient of internet is 0.001638 which denotes that $1 \%$ increase in internet leads $0.001638 \%$ increase in economic growth. The error 
correction term (ECT) coefficient is -1.205078 which is negative and significant, which confirms that economic growth, innovation and internet are cointegrated at $1 \%$ level of significance. This suggests that innovation and internet strongly influences economic growth.

Table 6: ARDL results when innovation $(I)$ is the dependent variable

\begin{tabular}{lllll}
\hline \hline Variable & Coefficient & Std. Error & t-Statistic & Prob. $^{*}$ \\
\hline \hline Long Run Equation & & & & \\
LOG(PI) & $0.088122^{* * *}$ & 0.001904 & 46.28584 & 0.0000 \\
DLOG(Y) & $3.916335^{* * *}$ & 0.287044 & 13.64367 & 0.0000 \\
Short Run Equation & & & & \\
\hline \hline ECT & $-0.449765^{* * *}$ & 0.087898 & -5.116897 & 0.0000 \\
DLOG(I(-1)) & -0.007382 & 0.092459 & -0.079839 & 0.9364 \\
DLOG(I(-2)) & -0.093592 & 0.071390 & -1.311006 & 0.1904 \\
DLOG(I(-3)) & 0.088657 & 0.069435 & 1.276845 & 0.2021 \\
DLOG(PI) & -0.053683 & 0.166358 & -0.322697 & 0.7470 \\
DLOG(PI(-1)) & -0.020148 & 0.101025 & -0.199436 & 0.8420 \\
DLOG(PI(-2)) & 0.063307 & 0.107023 & 0.591526 & 0.5544 \\
DLOG(PI(-3)) & -0.095019 & 0.103187 & -0.920841 & 0.3575 \\
DLOG(Y,2) & $-1.531637^{* *}$ & 0.736368 & -2.079987 & 0.0379 \\
DLOG(Y(-1),2) & $-2.132515^{* * *}$ & 0.800076 & -2.665392 & 0.0079 \\
DLOG(Y(-2),2) & -0.970261 & 0.624516 & -1.553621 & 0.1208 \\
DLOG(Y(-3),2) & -0.567672 & 0.627273 & -0.904985 & 0.3658 \\
C & $1.852615^{* * *}$ & 0.368517 & 5.027222 & 0.0000 \\
\hline \hline Table States the & & & & \\
\hline
\end{tabular}

Table 6 states the results of ARDL estimation of Equation (2). Long run equation results shows that economic growth $\log (\mathrm{Y})$ and internet $\log (\mathrm{PI})$ have a positive and significant impact on innovation. The error correction term (ECT) coefficient is 0.449765 which is negative and significant, which confirms that economic growth, innovation and internet are cointegrated at $1 \%$ level of significance in equation (2). This suggests that economic growth and internet strongly influences innovation.

\section{Conclusion}

The main purpose of this paper has been to highlight the connection between innovation and economic growth taking into consideration the matter of internet in economic growth and innovation. We try to take global evidence from 76 developed and developing countries during the period 1995 - 2016. By using the Panel ARDL model, the empirical results indicate that there is a positive unidirectional long run relationship between innovation and economic growth. 
Also, our estimation indicated that the internet has a positive effect on innovation and economic growth in the long run.

The clear inclusion of this investigation is that it supplies an authenticated search which could be valuable for policy makers, which should promote innovation and the use of internet as a strategic tool in various sectors, such as commerce, service, tourism, health, industry, education and agriculture to explore the role of the internet as a strategic tool in these sectors. We also propose to the countries of the world to develop procedures and strategies to facilitate access to more high-quality patents through the Internet through the expenditure on scientific research in various fields, in order to create many innovations and inventions through the rapid selection of patents aimed at achieving sophistication and sustainable development. 


\section{References}

Choi, C. and M. H. Yi (2009). The effect of the Internet on economic growth: Evidence from cross-country panel data. Economics Letters, 105, 39-41.

Hasan, I. and Tucci, C.L (2010). The innovation-economic growth nexus: global evidence, Research Policy, Vol. 39(10), 1264-1276.

Im, K.S., Pesaran, M.H., Shin, $Y$ (2003). Testing for unit roots in heterogeneous panels. Journal of Econometrics 115, 53-74.

Kao, C. (1999). Spurious regression and residual-based tests for cointegration in panel data. Journal of Econometrics, 90, 1-44.

Levin, A., Lin, C. F. and Chu, C. S. J (2002). Unit root tests in panel data: asymptotic and finite sample properties, Journal of Econometrics 108, 1-24.

Mabrouki, M (2018). Supporting economic growth through innovation: How does human capital influence the rate of growth? Economics Bulletin, AccessEcon, vol. 38(2), 957-972.

Maddala, G.S and Wu, S (1999). A comparative study of unit root tests with panel data and a new simple test. Oxford Bulletin of Economics and Statistics 61, 631652.

Pesaran, M. H., Shin, Y., and Smith, R. P. (1999). Pooled Mean Group Estimation of Dynamic Heterogeneous Panels. Journal of the American Statistical Association, 94(446), 621-634.

Romer, P.M (1986). Increasing returns and long-run growth. Journal of Political Economy 94 (5), 1001-1037.

Romer, P.M (1990). Endogenous technological change. Journal of Political Economy 98 (5), S71-S102.

Schumpeter, J.A (1932). Capitalism, Socialism, and Democracy. Harper and Brothers, New York.

Saidi, K and Mongi, C (20.18). The Effect of Education, R\&D and ICT on Economic Growth in High Income Countries, Economics Bulletin, AccessEcon, 38(2), 810-825.

Stokey, N.L (1995). R\&D and economic growth. Review of Economic Studies 28 (4), 1661-1707.

Tripathi, M and Inani, S.K (2016). Does internet affect economic growth in subSaharan Africa?', Economics Bulletin, AccessEcon, 36 (4), 1993-2002.

Zaghdoudi, T (2017). Internet usage, renewable energy, electricity consumption and economic growth: Evidence from developed countries, Economics Bulletin, AccessEcon, Volume 37(3),1612-1619. 